\title{
Green Technology and Sustainable Development of Renewable Energy
}

\author{
Dr. Suzana Yusup * (Associate Professor, Chemical Engineering Department, Universiti \\ Teknologi PETRONAS, Malaysia) \\ 31750, Tronoh. Perak., Malaysia \\ Tel. No.: +605-3688217 Fax No. +605-3688204 \\ Received July 12, 2016; Published July 15, 2016
}

Carbon dioxide $\left(\mathrm{CO}_{2}\right)$ and other greenhouse gases $(\mathrm{GHG})$ emissions, which cause global warming, have become a major worldwide concern with ten global 'mega' challenges that are currently impacting the planet in particular climate change, water, energy, and material resource scarcity. Increase in urbanization rate will continue to increase its need for natural resources, building materials, power and electricity, water, etc. that leads to bio-capacity deficit with a sharp increase in generation of ecological footprints. Power-generating plants running on fossil fuels have been identified as the main source of greenhouse gases (GHG). Approximately, $80 \%$ of the world primary energy consumption is still dependent on fossil fuels; thus, the substitution by renewable energy sources, in conjunction with other clean energy sources, appears to be the best and necessary alternative. There are many other sources of renewable energy such as solar, wind, and geothermal, but biomass have been receiving a lot of attention lately. Biomass has gained increased attention in the past decade because it does not only provide an effective option for the provision of energy services from a technical point of view, but also based on resources that can be utilized on a sustainable basis all around the globe. Another benefit of biomass utilization is that this resource can be converted to $\mathrm{C} 3-\mathrm{C} 4$ hydrocarbons and/or synthetic gas $\left(\mathrm{H}_{2}\right.$ and $\left.\mathrm{CO}\right)$.

Statistics shows that the urban areas with industrial, residential and commercial activities are the large energy "deficit zones". Thus, the transfer of biomass energy sources from the "surplus zones", which are those surrounding rural / plantation areas to the major urban cities, can be a solution that bring numerous benefits to the regions: (i) Environmental - minimization of $\mathrm{CO}_{2}$ emissions and other gases of the greenhouse effect (ii) Energy - improvement in the regional energy balance, reinforcement of energy independence, and (iii) Economical - maximization of the utilization of local energy sources and adding the value to the "waste".

There is a great potential for exploitation of local energy sources from wastes but the strength of policy support and stimulation measures are far from sufficient. At this moment, there is lack of studies about the integration of different types of wastes and the application of green technology approach, in addition to proper supply chain analysis and synthesis for waste-to-energy (WTE) system. These missing studies are crucial for solving both energy and environmental problems especially in the urban area. Further innovative and cost effective process needs to be developed to ensure the competitiveness of green industry. Producing biodiesel from non-edible feedstock is one of the solutions to reduce the import volume. Furthermore, public awareness and acceptance on the 
utilization of green fuels needs to be promoted and increased. Knowledge dissemination on the advantages of the biofuel utilization in the transportation sectors could be achieved through outreach initiatives to young minds and public.

Increasing demand of transportation fuel has made utilizing biofuels more attractive since it helps to reduce $\mathrm{CO}_{2}$ to $78.45 \%$ compared to if purely fossil fuel based is utilized. The sector which emits the most $\mathrm{CO}_{2}$ is the transportation sector. Energy for transportation is projected to be the fastest growing sector during the next five years, expanding at an annual rate of 5.3\%. Non-edible resources as fuel are thus important to avoid food vs fuel crisis and reduce dependency on fossil fuel. Furthermore, world population is projected to grow from 6.5 billion in 2005 to nearly 9.2 billion by 2050 . To feed a population of more than 9 billion, global food production must be doubled by 2050 . Additionally, reliance on a single source of feedstock for biodiesel production has its setback. Thus, diversification of the feedstock towards non-edible materials with a minimal retrofit to existing production facilities will help to overcome the situation. Sustainable development of the energy sector is one of the key factors to maintain economic competitiveness and progress.

The initiative of the Green Technology promotes minimization growth of energy consumptions while enhancing economic development. In addition, it will increase national capability, capacity and awareness for innovation in Green Technology. Overall, the policies and incentives on renewable energy are important to promote low carbon economy and society in future.

Article copyright: (C) 2016 Suzana Yusup. This is an open access article distributed under the terms of the Creative Commons Attribution 4.0 International License, which permits unrestricted use and distribution provided the original author and source are credited. 